\title{
Preliminary Studies on Plants with Anthelmintic Properties in Kashmir-The North-West Temperate Himalayan Region of India
}

\author{
Khurshid A. Tariq ${ }^{1}$, Mudasir A. Tantry ${ }^{2}$ \\ ${ }^{1}$ Department of Zoology, Islamia College of Science and Commerce, Srinagar, India \\ ${ }^{2}$ Drug Standardisation Research Unit, Regional Research Institute of Unani Medicine (CCRUM), Srinagar, India \\ Email: \{drkatariq, mudaek\}@yahoo.co.in
}

Received March 24, 2011; revised October 22, 2011; accepted February 10, 2012

\begin{abstract}
There is a growing interest in traditional uses of plants for health care among different communities especially in the developing countries. Kashmir valley is a temperate agro-climatic zone of north-west temperate Himalayan region of India and is blessed with a diverse variety of medicinal flora. The traditional uses of plants against parasitic infections in human beings and their live-stock is a common practice in the valley as most of the populations are rural and conventional veterinary drugs are very expensive and therefore unaffordable. This study is an ethno-botanical survey of those plant species traditionally used as anthelmintic that may warrant scientific validation for efficacy. The survey utilized well structured questionnaire and detailed discussions and recorded 44 plant species belonging to 37 genera and 26 families claimed as traditional anthelmintics in different preparations and forms. Out of these some plant species like Artemisia absinthium (tethwen) and Achillea millifolium (pahel-ghassa) were scientifically validated for their claimed anthelmintic action against gastrointestinal nematode infections in sheep. A few of other plants like Allium sativum (rohun), Myrsine africana have been scientifically validated for their claim by other people in various parts of the world. These plants together with other species reported in this study could be further scientifically evaluated for in vitro and in vivo anthelmintic activity against a diverse variety of parasitic groups in host and non host animals. That will lay a foundation and set a targeted platform for pharmacological studies and development of novel anthelmintic products to fill a gap in the anthelmintic drug industry, which is facing the crisis of anthelmintic resistance to conventional anthelmintic drugs.
\end{abstract}

Keywords: Ethno-Veterinary; Anthelmintic; Helminth Infection; Animals; Medicinal Plants

\section{Introduction}

Humans use plants for their basic needs like feeding, clothing, sheltering, hunting and nursing. As source of medicines, plants have formed the basis for sophisticated traditional systems and continue providing mankind with new remedies. There has been a times immemorial linkage between human civilization and the use of plants. Much of the world's population depends on traditional medicines to meet their daily health requirements. In ethno-medicine, at least $80 \%$ of the world's population in developing countries uses plant materials as their source of primary health care [1]. It is now a well established fact that $25 \%$ of all medical prescriptions are based on substances derived from plants or plant-derived synthetic analogues.

Helminth parasites are a major problem in animals throughout the world resulting in significant production losses as the performance of animals is inversely corre- lated with the intensity of helminth infections. Prophylactic treatment with synthetic anthelmintics is the primary control measure for helminth infections in animals in developed and developing countries. However, sporadic incidences of anthelmintic resistance have been reported in helminth populations and there has been a continual increase in the number of evidences outlining incidences of resistance to anthelmintics. In the absence of forthcoming anthelmintics of high efficacy, a shift towards other less conventional methods such as medicinal plants may provide a solution.

Evidence of the anthelmintic properties of plants and plant extracts is derived primarily from ethno-veterinary sources. The use of ethno-veterinary plant preparations have been documented in different parts of the world [2-8]. There has been a growing interest in alternative anthelmintics derived from plants in view of the high cost of conventional anthelmintics and the drug resis- 
tance. This discipline these days is gaining ample scientific validation for the appropriate applications as alternative anthelmintic drugs.

A lot of work has been done in the field of plant anthelmintics including both ethnobotanical surveys and scientific validation of their anthelmintic efficacies in many parts of the world. Unfortunately, no such work has been done so far in Kashmir valley, India. There is a need to explore this natural treasure in this geographically peculiar region before being it is lost owing to the worldwide rapid decline in medicinally important flora. The valley harbours a rich and unique flora of medicinal plants being distinct from those in the rest of the country and other parts of the world. Owing to its very rich variety of medicinal plants, Kashmir has been a favourable place for local "Hakims" to practice Unani System of Medicine [9]. The present study was aimed at to survey the plants with traditional anthelmintic usage in Kashmir valley.

\section{Study Area}

Kashmir valley is a temperate agro-ecological zone of Jammu and Kashmir State of Indian sub-continent. It lies between $33^{\circ} 20^{\prime}$ and $34^{\circ} 54^{\prime} \mathrm{N}$ latitudes and $73^{\circ} 55^{\prime}$ and $75^{\circ} 35^{\prime} \mathrm{E}$ longitudes, covering an area of $15,948 \mathrm{sq} \cdot \mathrm{km}$. Topographically, it is a deep elliptical bowl shaped valley bounded by lofty mountains of the Pir Panjal range in the south and south west and the great Himalayan range in the north and east, with $64 \%$ of the total area being mountainous. Kashmir valley forms an important region of the North West Temperate Himalayan biographic zone in India. The entire territory is a mass of mountain ranges, springs, lakes, tableland and alpine/subalpine pastures. The floristic diversity of Kashmir is considerably rich. About four hundred plus medicinal plants are prescribed in the British Pharmacopoeia. Majority of the people practice agriculture and live stock husbandry is an important source of income.

\section{Methodology}

The present study was carried out through field surveys during the period 2007-2009 in the Kashmir valley. A well structured questionnaire was used for the interview. Interviews were taken from local elder and experienced people, herbalists for identification of medicinal plants used as anthelmintics in folklore. The interviews were conducted in the local and other regional languages. Each interviewee was taken to the field for the correct identification of the plant species. Repeated queries were made to get the data confirmed. The fresh plants and plant parts were collected for correct identification. All the information about vernacular name, use, method of preparation and administration, obtained from the informants through individual interviews was carefully collected and analysed. The informants were selected on the basis of the distribution of botanical folk knowledge in the population. In some cases, the informants invited us to their houses to show various plants/plant parts collected for remedial usage against parasites. For all the plant species direct observations and local literature $[10,11]$ were consulted to reveal more details about the identified plants.

\section{Results and Discussion}

The present survey during the period from 2007 to 2009 resulted in the identification of a variety of plant species used in folklore as anthelmintic in domestic animals and human beings in Kashmir valley. Some specific plant species are said to be effective against specific parasites e.g. Punica granatum (Daein) and Cucurbita sp. (pumpkin) is exclusively employed to treat cases of parasitism due to Taenia saginata infection while as Artemisia absinthium (Tethwen) is given only to treat infections with nematodes. Traditional knowledge reported for anthelmintic usage of 44 plants of 37 genera belonging to 26 families is presented in Table 1.

Based upon the indigenous knowledge reported during the study, the area comprises a valuable medicinal flora with anthelmintic properties. Helminth infections are a major cause for reduced productivity in live stock, particularly those owned by the poor worldwide. Helminth control programs, based on improvement of farm management and synthetic anthelmintic treatments are often impracticable in developing countries due to relatively high price of these anthelmintics.

Phyto-medicine is an integral part of traditional veterinary practice in many developing countries in Asia and Africa. In Indo-Pak subcontinent, Ayurvedic and Unani medicinal systems are very popular and people have been using plants for the treatment of their own ailments as well as for their domesticated animals in view of the rising costs of conventional veterinary drugs. Medicinal plants may become good alternatives for modern synthetic anthelmintics in small holder farms if their efficacy can be proved scientifically under controlled studies. The herbal ethno-veterinary remedies are likely to gain importance in the management of livestock diseases perhaps of the fact that herbal remedies are known to be broad spectrum and therefore may be a future answer to the development of resistance of pathogens to conventional drugs [12].

The main methods for control of helminthes are prophylactic treatments with synthetic anthelmintics. These drugs are expensive and there are several factors that highlight the need to alternative control strategies to parasite control. For example, the rapid development of anthelmintic resistance, the perceivable drug residues in 
Table 1. List of plant species with traditional anthelmintic activities reported in domestic animals and human beings in the Kashmir valley, India.

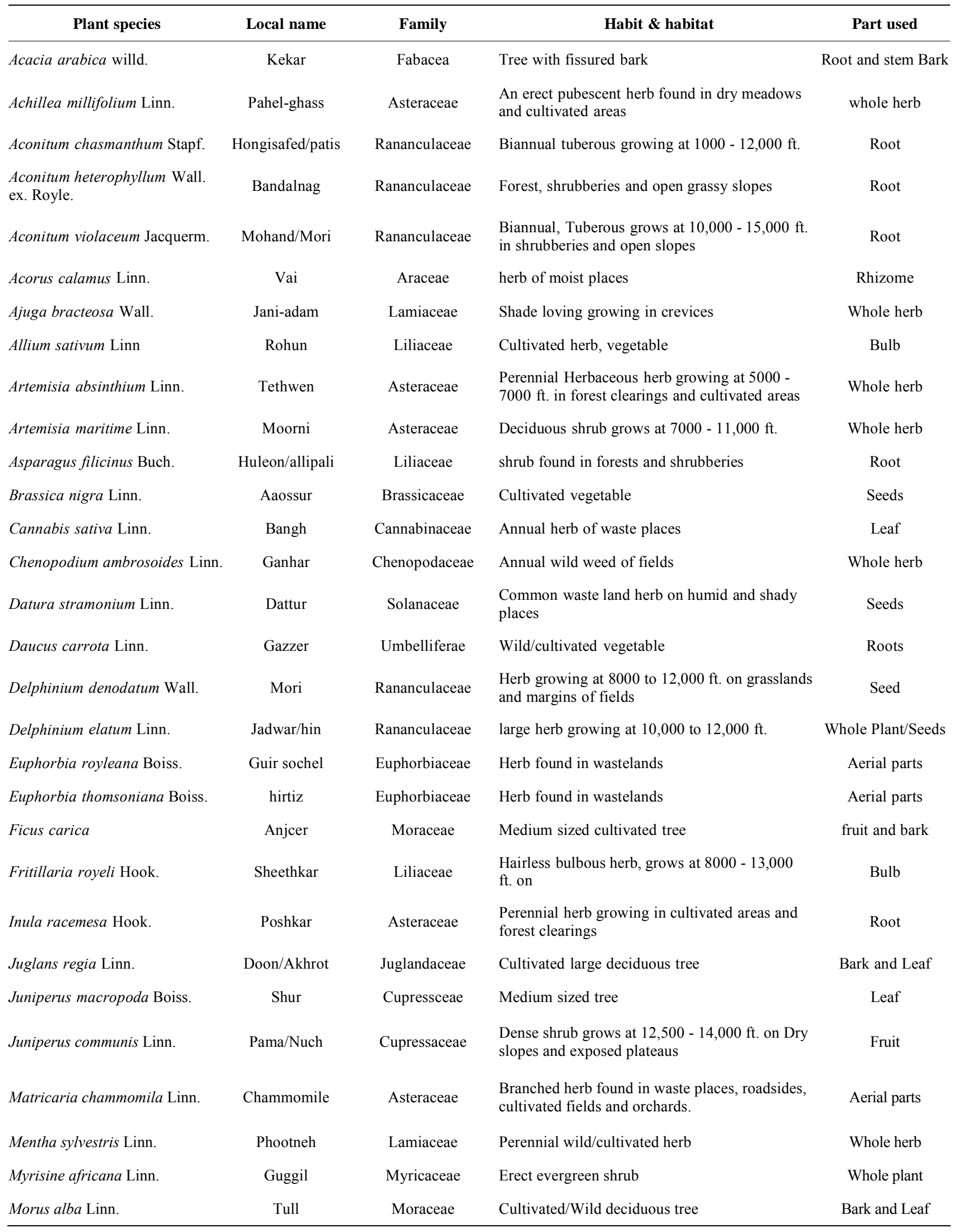




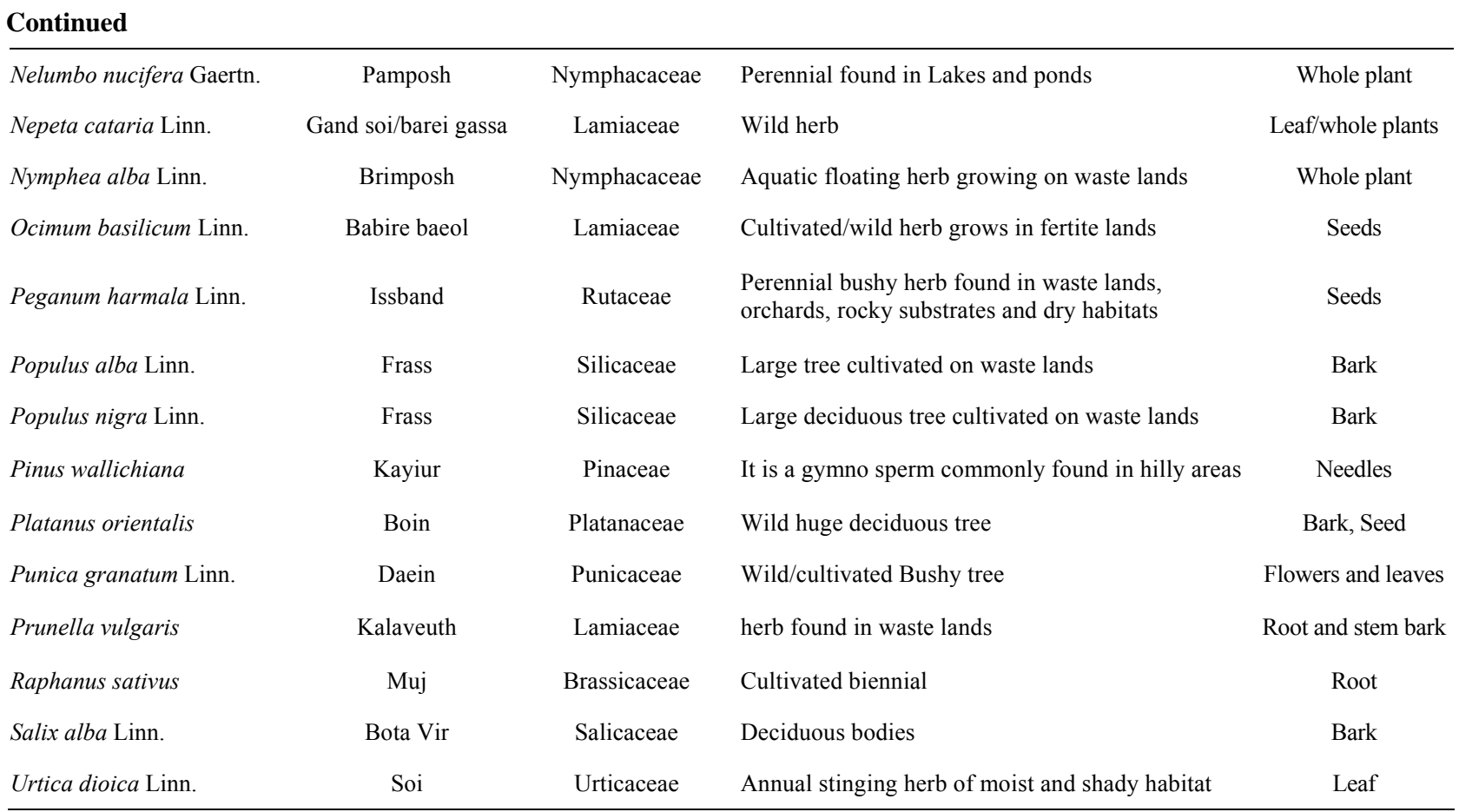

animal products, lack of veterinary services in remote pastoralist areas. All these factors have spurred the quest to develop sustainable, effective and safe alternatives to conventional anthelmintics. Studies from various parts of the world have shown that certain plant species not only affect the nutrition of animals but effectively reduce the degree of parasite infestation in sheep and are promising alternatives to conventional anthelmintics $[13,14]$. The natural compounds derived from plants are more stable as these are mostly plant secondary metabolites synthesized over a long period of time. Furthermore, the natural compounds also provide greater structural diversity than synthetic ones and therefore are a source of low molecular weight structures active against a wide range of target agents and this diversity can preclude the occurrence of resistance.

Studies are available from various parts of the world wherein the anthelmintic efficacies of some of the plants reported also in this survey have been carried out. For example Kashiya [15], observed a significant decrease in faecal egg counts in animals treated with dried leaves of Acacia nilotica $(\mathrm{P}<0.05)$ and also reported a reduction of $34 \%$ in worm burdens in animals treated with Acacia karoo. Khobragrade [16] reported a complete cessation of motility of Bunostomum trigonocephalum worms after exposure to crude aqueous extracts of Allium sativum. Such an activity has also been reported for some plants like that of Chenopodium album, Sorghum extract [17], Allium sativum, Zingiber officinale, Curcurbita mexicana and Ficus religiosa [18]. Seeds of Peganum harmala contain an active constituent-Tetra-hydro-harmin that has been claimed to be active against mixed gastrointestinal nematode infection in goats [19]. The anthelmintic activity of plant extracts can be either due to direct action of extract on the worms or through induction of GI irritation and diarrhoea, which causes dislodgment of resident worms. Plants that appear to have direct anthelmintic action include $A$. absinthium and $C$. ambrosioides that in vivo cause severe GI irritation and in vitro cause paralysis and ultimately death of worms. Chemical analysis of A. absinthium has shown that its volatile oil is rich in thujone $(\alpha$ and $\beta$ ), which has been earlier reported as an anthelmintic [20]. In Turkish folk medicine, A. absinthium has also been used as an anthelmintic, besides its other uses such as antipyretic, antiseptic, tonic, diuretic and for the treatment of stomach aches [21].

In one of our study on evaluation of anthelmintic efficacy of $A$. absinthium, the crude ethanolic extracts resulted in $90.46 \%$ faecal egg count reduction followed by $82.85 \%$ when mixed species of gastrointestinal nematodes in the sheep were treated with ethanolic extracts at $2.0 \mathrm{~g} \cdot \mathrm{kg}^{-1}$ and $1 \mathrm{~g} \cdot \mathrm{kg}^{-1} \mathrm{bw}$ respectively [22]. Iqbal observed a maximum faecal egg count reduction of $67.2 \%$ on day 14 PT with CAE of Artemisia absinthium at 3 $\mathrm{g} \cdot \mathrm{kg}^{-1}$ body weight [23]. Iqbal showed that the crude powder and crude aqueous extracts of ginger exhibited a dose and a time dependent anthelmintic activity against GI nematode of sheep with the respective maximum faecal egg count reduction of $25.6 \%$ and $66.6 \%$ on day 10 PT [24].

The in vivo anthelmintic activity (in terms of reduction of nematode egg out put) of crude aqueous and ethanolic 
extracts of A. millifolium in sheep naturally infected with mixed species of GI nematodes demonstrated the significant anthelmintic activity in either of the doses and extracts tested. Various constituents have been identified and isolated from $A$. millifolium like $\alpha$-pinene, $\alpha$-thujene, $\beta$-pinene, $\alpha$-terpene, geranial, eugenol, sesquiterpenes hydrocarbons, and guainol have been identified from its roots [25] and any one of them could be the potential molecule showing anthelmintic activity. Eugenol has been earlier confirmed to possess anthelmintic activity [26].

Further studies on standardization of doses and to identify the mechanism/s of mode/s of action of these extracts against nematodes will be a welcome step. The novel plant anthelmintics with new mechanisms of action will be highly efficacious because the resistant populations of helminth parasites against conventional anthelmintics are not able to manifest the resistance potential towards the newly introduced drugs. However, simultaneously plant anthelmintics will generate new selection pressure for the parasitic organisms to develop anthelmintic resistance, because resistance can develop in the target parasites to any chemical group. In natural populations, there is always a genetically resistant group of individuals which can get selected against the routinely administered drugs-natural selection. Therefore, we can not break the process of selection of resistance but we can delay the selection process by providing alternate and novel drugs with reliable and standardized doses in replacement to conventional drugs. Strategies are to be developed to slow down the evolution of anthelmintic resistance and our aim should be to sustain the livestock in its presence. Although it will take time and much of the patience and expertise to standardize the plant anthelmintics and address the recent emergent trends in anthelmintics, the use of herbal remedies as anthelmintics based on local plants will at least offer a cheap, reliable and a readily available alternative to highly expensive and unavailable conventional anthelmintics to the poor farmers worldwide.

The development of traditional herbal anthelmintics can be initiated with collection of information concerning species of plants, which have been used to treat parasites. The plants reported in this study could be scientifically evaluated for in vitro and in vivo anthelmintic activity against different helminth parasites to validate their traditional anthelmintic usage. Our group is actively looking into this aspect of traditional anthelmintic approach in Kashmir valley. Tariq and others evaluated the in vitro and in vivo anthelmintic activity of Artemisia absinthium and Achillea millifolium against gastrointestinal nematodes of sheep and the findings therein validated the traditional usage of these plant species [27].

Whole plant consumption has in several cases shown good anthelmintic effects against GI nematodes of sheep.
This could be either due to direct toxic effects on the worms or it can be indirect due to changes in the gut environment that favour low fecundity and worm expulsion. The mechanisms whereby the consumption of certain plants and plant extracts can affect parasite viability, mobility and fecundity both in vitro and in vivo are largely unknown. For some plants it has been suggested that their consumption could be associated with an enhanced immune response of the host towards the parasite, as a result of nutrient supplementation and thus improved nutrition [28]. Many of the plants that have been reported to have anthelmintic properties actually contain compounds that are directly active against parasites. In many cases these active compounds are plant secondary metabolites (PSM) [29]. Saponins, alkaloids, non-protein amino acids, tannins and other Polyphenols, lignins, glycosides, are all PSM and some of them have been considered responsible for the antiparasitic effect of plants. Condensed Tannins (CT) have been considered responsible for the anthelmintic effect caused by Rasp berries [30] Quibracho in both sheep and goats [31-35].

The role of plants in extending the use, and increasing the efficacy of existing anthelmintics, should be explored especially plants that might help in reversing resistance of some of the preparations in the market. Studies need to be carried out world wide to identify more plants with medium to high efficacy against nematode parasites. Different strategies have already been used and should be further developed to determine a sound and practical basis for the selection of plants for scientific examination on their anthelminthic properties. One of the strategies involves the use of information derived from ethno-veterinary medicine (EVM). In many instances, EVM remedies have been identified for the treatment of different conditions, but mostly without validation. Despite ample evidence of antiparasitic properties of several plants (or plant products), there is still a need to provide validated experimental data of biological meaningful reductions in infection levels to support the view that plants may play a direct role in the sustainable control of helminth infections under farming situation.

\section{Acknowledgements}

KT and MT thank Center for Scientific and Industrial Research (CSIR) and Center Council for Research in Unani Medicine (CCRUM) New Delhi respectively for providing fellowship.

\section{REFERENCES}

[1] N. R. Farnsworth, O. Akerele, A. S. Bingel, et al., "Medicinal Plants in Therapy," Bulletin of the World Health Organisation, Vol. 63, No. 6, 1985, pp. 965-981.

[2] M. S. Akhtar, Z. Iqbal, M. N. Khan and M. Lateef, “An- 
thelmintic Activity of Medicinal Plants with Particular Reference to Their Use in Animals in the Indo-Pakistan Subcontinent," Small Ruminant Research, Vol. 38, No. 2, 2000, pp. 99-107. doi:10.1016/S0921-4488(00)00163-2

[3] Z. Iqbal, M. S. Akhter, S. Zia-UD-Din, et al., "Herbal Dewormers in Livestock-A Traditional Therapy International," Journal of Agriculture and Biology, Vol. 5, No. 2 2003, pp. 199-206.

[4] P. J. Waller, G. Bernes, S. M. Thamsborg, A. Sukura, S. H. Richter, K. Ingebrigtsen and J. Hoglund, "Plants as De-Worming Agents of Livestock in the Nordic Countries: Historical Perspective, Popular Beliefs and Prospects for the Future," Acta Veterinaria Scandinivia, Vol. 42, No. 1, 2001, pp. 31-44. doi:10.1186/1751-0147-42-31

[5] S. Athanasiadou, I. Kyriazakis, F. Jackson and R. L. Coop, "Direct Anthelmintic Effects of Condensed Tannins towards Different Gastrointestinal Nematodes of Sheep: In Vitro and in Vivo Studies," Veterinary Parasitology, Vol. 99, No. 3, 2001, pp. 205-219. doi:10.1016/S0304-4017(01)00467-8

[6] J. B. Githiori, J. Hoglund, P. J. Waller and R. L. Baker, "Anthelmintic Activity of Preparations Derived from Myrsine Africana and Rapanea Melanophloeos against the Nematode Parasite, Haemonchus Contortus, of Sheep," Journal of Ethnopharmacology, Vol. 80, No. 2-3, 2002, pp. 187-191. doi:10.1016/S0378-8741(02)00030-2

[7] Z. Iqbal, M. Lateef, A. Jabbar, G. Muhammah and M. N. Khan, "Anthelmintic Activity of Calotropis Procera (Ait.) Ait. F. Flowers in Sheep," Journal of Ethnopharmacology, Vol. 102, No. 2, 2005, pp. 256-261. doi:10.1016/j.jep.2005.06.022

[8] Z. Iqbal, M. Lateef, M. S. Akhter, M. N. Ghayur and A. H. Gilani, "In Vivo Anthelmintic Activity of Ginger against Gastrointestinal Nematodes of Sheep," Journal of Ethnopharmacology, Vol. 106, No. 2, 2006, pp. 285-287. doi:10.1016/j.jep.2005.12.031

[9] G. H. Dar, R. C. Bhagat and M. A. Khan, "Biodiversity of the Kashmir Himalaya," Valley Book House, Srinagar, 2002.

[10] M. K. Koul, "Medicinal Plants of Kashmir and Ladakh," Industrial Publishing Company, New Delhi, 1997.

[11] The Wealth of India, "National Institute of Science Communication and Information Resources," CSIR, New Delhi, 2003-2005.

[12] M. Mwale, E. Bhebhe, M. Chimonyo and T. E. Halimani, "Use of Herbal Plants in Poultry Health Management in the Mushagashe Small-Scale Commercial Farming Area in Zimbabwe," International Journal of Applied Research in Veterinary Medicine, Vol. 3, No. 2, 2005, pp. 163-170.

[13] J. B. Githiori, S. Athanasiadou and S. M. Thamsborg, "Use of Plants in Novel Approaches for Control of Gastrointestinal Helminths in Livestock with Emphasis on Small Ruminants," Veterinary Parasitology, Vol. 139, No. 4, 2006, pp. 308-320. doi:10.1016/j.vetpar.2006.04.021

[14] G. C. Waghorn and W. C. McNabb, "Consequences of Plant Phenolic Compounds for Productivity and Health of Ruminants," Proceedings of the Nutrition Society, Vol. 62, No. 2, 2003, pp. 383-392. doi:10.1079/PNS2003245
[15] C. Kahiya, S. Mukaratirwa and S. M. Thamsborg, "Effects of Acacia Nilotica and Acacia Karoo Diets on Haemonchus Contortus Infection in Goats," Veterinary Parasitology, Vol. 115, No. 3, 2003, pp. 265-274. doi:10.1016/S0304-4017(03)00213-9

[16] V. R. Khobragade, C. R. Jangede and K. D. Maske, "In Vitro Anthelmintic Trial of Extract of Allium Sativum Linn against Bunostomum Trigonocephalum in Goats," Journal of Veterinary Parasitology, Vol. 2, No. 4, 1994, pp. 97- 98 .

[17] Z. Iqbal, M. A. Munir, M. N. Khan, M. S. Akhter and I. Javed, "In Vitro Inhibitory Effect of Sorghum Bicolor on Hatching and Moulting of Haemonchus Contortus Eggs," International Journal of Agriculture and Biology, Vol. 3, No. 4, 2001, pp. 451-453.

[18] Z. Iqbal, Q. K. Nadeem, M. N. Khan, M. S. Akhtar and F. N. Waraich, "In Vitro Anthelminitc Activity of Allium Sativum, Zingiber Officinale, Curcurbita Mexicana and Ficus Religiosa," International Journal of Agriculture and Biology, Vol. 3, No. 4, 2001, pp. 454-457.

[19] M. S. Akhtar and I. Ahmad, "Evaluation of Antinematodal Efficacy of Tetrahydroharmine in Goats," Veterinarski Arhiv, Vol. 61, 1999, pp. 307-311.

[20] J. P. Meschler and A. C. Howlett, "Thujone Exhibits Low Affinity for Cannabinoid Receptors but Fails to Evoke Cannabimimetic Responses," Pharmacology Biochemistry and Behaviour, Vol. 62, No. 3, 1999, pp. 413-480. doi:10.1016/S0091-3057(98)00195-6

[21] T. Baytop, "Therapy with Medicinal Plants in Turkey," Istanbul University Press, Istanbul, 1984.

[22] K. A. Tariq, M. Z. Chishti, F. Ahmad and A. S. Shawl, "Activity of Extracts of Artemisia Absinthium against Ovine Nematodes," Veterinary Parasitology, Vol. 160, No. 1-2, 2009, pp. 83-88. doi:10.1016/j.vetpar.2008.10.084

[23] Z. Iqbal, M. Lateef, M. Ashraf and A. Jabbar, "Anthelmintic Activity of Artemisia Brevifolia in Sheep," Journal of Ethnopharmacology, Vol. 93, No. 2-3, 2004, pp. 265-268. doi:10.1016/j.jep.2004.03.046

[24] Z. Iqbal, M. Lateef, M. S. Akhter, M. N. Gayur and A. H. Gilani, "In Vivo Anthelmintic Activity of Ginger against Gastrointestinal Nematodes of Sheep," Journal of Ethnopharmacology, Vol. 106, No. 2, 2006, pp. 285-287. doi:10.1016/j.jep.2005.12.031

[25] P. M. L. Lourenco, A. C. Figueiredo, J. G. Barasso, L. G. Pedro, M. M. Oliveira, S. G. Deans and J. J. C. Scheffer, "Essential Oils from Hairy Root Cultures and from Plant Roots of Achillea Millifolium," Phytochemistry, Vol. 51, No. 5, 1999, pp. 637-642. doi:10.1016/S0031-9422(99)00083-7

[26] M. K. Asha, D. Prashanth, B. Murali, R. Padmaja and A. Amit, "Anthelmintic Activity of Essential Oil of Ocimum Sanctum and Eugenol," Fitoterapia, Vol. 72, No. 6, 2001, pp. 669-670. doi:10.1016/S0367-326X(01)00270-2

[27] K. A. Tariq, M. Z. Chishti, F. Ahmad and A. S. Shawl, "Anthelmintic Efficacy of Achillea Millifolium against Gastrointestinal Nematodes of Sheep: In Vitro and in vivo Studies," Journal of Helminthology, Vol. 82, No. 3, 2008, 
pp. 227-233. doi:10.1017/S0022149X08972515

[28] S. Athanasiadou and I. Kyriazakis, "Plant Secondary Metabolities: Antiparasitic Effects and Their Role in Ruminant Production Systems," Proceedings of Nutritional Society, Vol. 63, No. 4, 2004, pp. 631-639. doi:10.1079/PNS2004396

[29] I. Muller-Harvey and A. B. McAllan, "Tannins: Their Biochemistry and Nutritional Properties," Advances in Plant Cell Biochemistry and Biotechnology, Vol. 1, 1992, pp. 151-217.

[30] C. E. Taylor and A. F. Murant, "Nematicidal Activity of Aqueous Extracts from Rasperry Canes and Roots," Nematologica, Vol. 12, No. 4, 1996, pp. 488-494. doi:10.1163/187529266X00310

[31] S. Athanasiadou, I. Kyriazakis, F. Jackson and R. L. Coop, "Consequences of Long-Term Feeding with Condensed Tannin on Sheep Parasitized with Trichostrongylus Colubriformis," International Journal of Parasitolog, Vol. 30, No. 9, 2000, pp. 1025-1033.

doi:10.1016/S0020-7519(00)00083-7
[32] S. Athanasiadou, I. Kyriazakis, F. Jackson and R. L. Coop, "Effect of Short-Term Exposure to Condensed Tannins on Adult Trichostrongylus Colubriformis," Veterinary Research, Vol. 146, No. 25, 2000, pp. 728-732.

[33] S. Athanasiadou, I. Kyriazakis, F. Jackson and R. L. Coop, "Direct Anthelmintic Effects of Condensed Tannins towards Different Gastrointestinal Nematodes of Sheep: In Vitro and in Vivo Studies," Veterinary Parasitology, Vol. 99, No. 3, 2001, pp. 205-219. doi:10.1016/S0304-4017(01)00467-8

[34] V. Paolini, J. P. Bergeaud, C. Grisez and F. Prevot, Ph. Dorchies and H. Hoste, "Effect of Condensed Tannins on Goats Experimentally Infected with Haemonchus Contortus," Veterinary Parasitology, Vol. 113, No. 3-4, 2003, pp. 253-261. doi:10.1016/S0304-4017(03)00064-5

[35] A. Jabbar, M. A. Raza, Z. Iqbal and M. N. Khan, "An Inventory of the Ethnobotanicals Used as Anthelmintics in the Southern Punjab (Pakistan)," Journal of Ethnopharmacology, Vol. 108, No. 3, 2006, pp. 152-154. doi:10.1016/j.jep.2006.04.015 